\title{
¿Así son, así se imaginan ellos, o así los imaginamos? Reflexiones sobre las transformaciones socioterritoriales del turismo residencial en Malinalco, México
}

Irma Ramírez. Universidad Autónoma del Estado de México, Toluca, México. Irma Cortés. Universidad Autónoma del Estado de México, Toluca, México. Maribel Osorio. Universidad Autónoma del Estado de México, Toluca, México. Rubén Nieto. Universidad Autónoma del Estado de México, Tenancingo, México.

RESUMEN | Las transformaciones espaciales - materiales y simbólicas- atribuibles al turismo residencial son correlativas a las sensaciones, pensamientos, sentimientos y creencias de los actores involucrados, por lo que estos deben considerarse en el estudio del fenómeno. El documento se basa en un enfoque epistemológico que subraya la importancia de la subjetividad no solo en la experiencia de un paisaje rural, sino también en su instrumentalidad, encabezada y conducida en Malinalco por un grupo de actores acaudalados, cuyo comportamiento confiesa un habitus (Bourdieu) aproximado cualitativamente. El imaginario de ese grupo incluye "la hacienda" como representación de "lo rural" y la ostentación como símbolo de estatus social y poder político, mientras el influjo de la modernidad y posmodernidad forma sus periferias, incrustándose en el poblado.

PALABRAS CLAVE | imaginarios urbanos, transformaciones socioterritoriales, mercado inmobiliario.

ABSTRACT | Both physical and symbolic spatial transformations attributed to residential tourism are correlative to sensations, thoughts, feelings and the belief of the actors involved; thereby, studies of the phenomenon should take them into account. The paper is based on an epistemological approach that emphasizes subjectivity, not only in the experience of a rural landscape, but also in its instrumentality. In Malinalco, the latter is led and driven by a wealthy set of actors whose behavior confesses a habitus (Bourdieu), which is approximated in this paper with qualitative methods. The imagery of that group includes "hacienda" as a representation of rurality, and ostentation as a political power and status symbol. Meanwhile, modernity and postmodernity shape their peripheries, which become embedded in the town.

KEYWORDS | urban imaginary, socio-territorial transformations, real estate market.

Recibido el 11 de enero de 2015, aprobado el 14 de junio de 2016

E-mails: I. Ramírez, iramirezdelao@gmail.com | I. Cortés, iycortess@uaemex.mx | M. Osorio, maribelosorio2@gmail.com | R. Nieto, rnieto@uaemex.mx 


\section{Introducción}

Malinalco es un pequeño poblado que en 2010 contaba con 25.624 habitantes (Ayuntamiento Constitucional de Malinalco, 2013), situado aproximadamente a $100 \mathrm{~km}$ de la Ciudad de México. En la época prehispánica fue un importante centro ceremonial; sus primeros poblamientos ocurrieron en el posclásico temprano como parte del área matlazinca, y su lengua existía desde el 600 d.C. Hay tres construcciones prehispánicas en el Cerro de los Ídolos; además de estas, se han localizado otros 35 sitios de vestigios arqueológicos en el municipio (Instituto Nacional para el Federalismo y el Desarrollo Municipal [Inafed], s.f). Según Beligand (1999, citado en Santiago, 2012), la transformación del territorio matlazinca se inició con su reorganización en encomiendas, que posteriormente derivaron en haciendas. Desde los años setenta recibe turismo rural y cultural, pero desde la construcción del club de golf (1993) arribó un segmento de turismo residencial, relacionado con la acelerada terciarización de la economía local, excesiva presión sobre los recursos naturales y emigración de pobladores (Royuela \& Ramírez, 2015). En 2005 fue nombrado "Pueblo con Encanto", y en 2010, "Pueblo Mágico". Se lo describió como:

Exuberante naturaleza, paisajes protegidos entre serranías, peñascos y verdores, arropados por un cielo solar y azul, por noches de estrellas centelleantes, sitio de murmullos de aves, resonancias de aullidos, de sabores de frutas, de aire cálido, de olores de vegetación tropical, pero más todavía de habitantes generosos, recónditos de mística... (Schneider, 1999)

\section{FIGURA I | Vista panorámica de Malinalco}

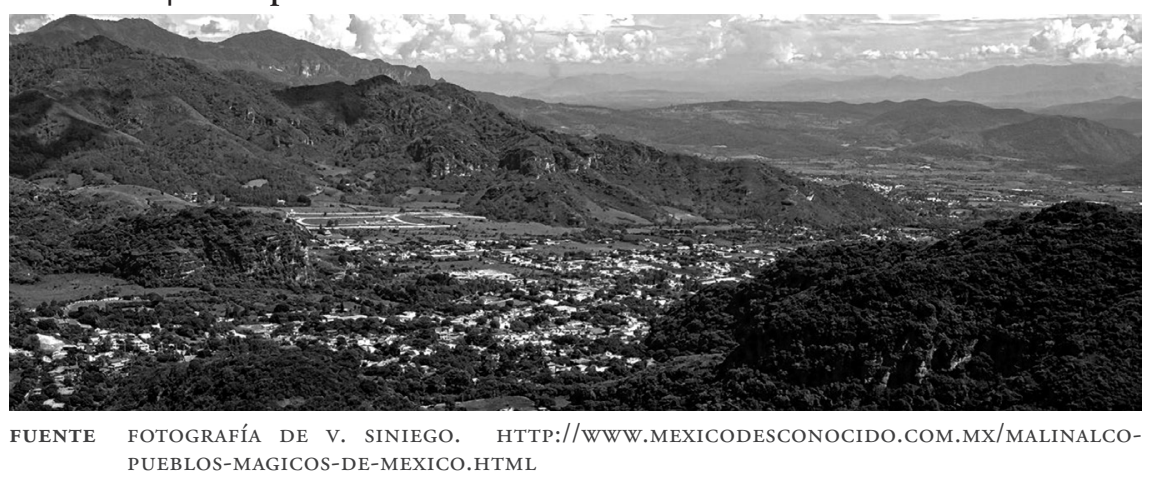

Una de las facetas más intrigantes de Malinalco es el tipo de compradores de terrenos o inmuebles, que lo elige para reposo o esparcimiento. Identificados como políticos, empresarios, gente del espectáculo e intelectuales, alcanzan muy altos ingresos. ¿Cómo perciben este pueblo, de manera que les despierta el interés en él? Aunque parezcan triviales, algunos autores sugieren lo deseable de conocer esas percepciones, tanto por las posibilidades de manejo (urbanístico, social, económico) que puedan derivarse de ellas, como para comprender el fenómeno. De 
hecho, aunque ha sido difícil describirlo conceptualmente y distinguirlo de la migración (Huete \& Mantecón, 2009; Mantecón, 2008), el turismo residencial ocasiona gran discusión, porque no solo están en juego sus motivaciones, sino sus consecuencias concretas (Huete, Mantecón \& Mazón, 2008). Esto último entraña transformaciones profundas -degradación de los recursos, cambios en la estructura laboral o islotes de "progreso" en medio de pobreza-, mientras sus motivaciones aluden a mentalidad, imaginarios, ideología, sentimientos, creencias y, en general, a todo lo subjetivo.

En la perspectiva de este escrito, estos dos grupos de aspectos se desprenden del fenómeno visto integralmente, de manera que el enfoque en uno u otro solo se debería al interés inmediato del investigador, pues no puede afirmarse que existan personas sin subjetividad, ni que en cualquier circunstancia actúen tales individuos.

\section{Metodología}

La trabazón entre lo personal y lo espacial ha sido gran inquietud de Lowenthal, quien expuso un enfoque epistemológico (1961) en el que se basa este documento. Formando parte de una tradición en la investigación de los imaginarios geográficos (que incluye a Harvey, Said, Cosgrove, Gregory, Soja), la propuesta de Lowenthal retomó la idea de Wright (1947) sobre la subjetividad como elemento clave de la diferenciación espacial. Tal enfoque atañe a la Geografía Humanista, tiene base fenomenológica, nació como reacción al cuantitativismo (Sanguin, 1981; Zusman, 2013), está emparentado con la Geografía Cultural, y se integra en la Comportamental y Perceptual (Ley, 2009; Tuan, 2003).

Fascinado por cómo la gente aprehende los paisajes y configura sus entornos materiales, a Lowenthal no le interesa el paisaje como cosa-en-sí-misma, sino el nexo entre las "imágenes efímeras de la mente" y las "cosas materiales significativas" (Olwig, 2003, p. 875). Para él, el lugar es importante como almacén del pasado: quiénes somos depende de quiénes éramos, y la percepción obedece a experiencia e imaginación (Tuan, 2003). Además de no estar aislada - pues sensación, pensamiento, sentimiento y creencia son simultáneos e interdependientes-, la percepción está condicionada cultural, social y territorialmente, y ya que todo conocimiento es subjetivo y objetivo, para evitar reduccionismos sin verosimilitud "requerimos hechos sin barnizar, experiencias frescas de primera mano, opiniones y prejuicios" (Lowenthal 1961, p. 258).

Así, Lowenthal estudió cómo la imaginación da sentido a las acciones, pensamientos y materialidades pretéritas y cómo las sociedades interactúan diferencialmente con el pasado (Zusman, 2013), pues este "no solo es evocado, está encarnado en las cosas que construimos y los paisajes que creamos" (Lowenthal, 1975, p. 6). De acuerdo con Sanguin (1981), Lowenthal y Prince (1964, 1965) trataron el paisaje como expresión viviente de los valores y gustos de un pueblo, y mostraron las preferencias por lo rural, viejo, bucólico y pintoresco, frente a lo urbano, nuevo e industrial (Zusman, 2013).

De lo anterior se propone que para comprender el turismo residencial, deben analizarse las percepciones e imaginarios que median la relación entre los sujetos y 
el ambiente. Por ello, este escrito se enfoca en los individuos como poseedores de una subjetividad que incide en la transformación espacial, pero aunque los perfiles de turismo residencial de Malinalco son peculiares, debe precisarse que el lugar comparte aspectos históricos, culturales, políticos y sociales con el país y con Latinoamérica, y se diferencia claramente de otros espacios; por ejemplo, en Espańa se observan grandes segmentos de jubilados europeos, no significativos en este caso.

Ya que en diversas investigaciones -incluyendo esta- no se logró una autodescripción de los turistas residenciales de Malinalco, además del enfoque descrito se aplican otras vías metodológicas, ya ensayadas. Por un lado, se incorporan impresiones y recuerdos de quienes viven o han pasado largo tiempo en Malinalco, que han alternado con turistas residenciales, o que han presenciado o participado en situaciones que reflejan sus ideas, con lo cual se propone una aproximación a su imaginario (Nieto, 2005). La obtención de esta información se basó en etnografía y observación participante (Ameigeiras, 2006), y se recuperó de: (i) investigaciones previas; (ii) una entrevista grupal a 12 pobladores y actores clave, que eligieron la anonimidad (PI: 15-06-2015); (iii) una entrevista de profundidad a uno de los autores (P2: 09-07-2014); (iv) una entrevista de profundidad a un residente (P3: 02-07-2014), y (v) declaraciones de actores expuestas a los autores (D I obs: 20-0408; D2obs: 09-07-14). Los datos cualitativos que involucran a los autores provienen de una larga trayectoria de investigación y de década y media en el poblado (por su trabajo) de uno de los autores, pero fueron seleccionados para la temática abordada. Y finalmente, la historia y actividades de los personajes mencionados por las fuentes se corroboraron en medios periodísticos e Internet.

La interpretación de la información retoma a otros investigadores, particularmente el tratamiento de Ponce (2010) que reconstruye el habitus (Bourdieu, 1988) de los actores estudiados (los hacendados): los esquemas generativos socialmente estructurados y conformados históricamente, desde los cuales los sujetos perciben el mundo y actúan en él, lo que implica su interiorización. El habitus se aprende vía familiarización práctica, de modo que a cada posición social corresponden distintos universos de experiencias, ámbitos de prácticas, categorías de percepción y apreciación (Ponce, 2010, p. 52). Al incluir las perspectivas de los autores, el escrito supone una propuesta epistemológica y metodológica particular que no pretende neutralidad; por el contrario, asume que toda interpretación conlleva nuestra subjetividad y que los imaginarios condicionan el trabajo científico (Berdoulay, 2012, p. 53). Siendo así, el trabajo se declara crítico a los estudios que soslayan los esfuerzos reflexivos y a las epistemologías que rechazan la expresión de todas las voces en nombre de una supuesta objetividad o pureza metodológica (Ren, Pritchard \& Morgan, 2010).

Con base en estos enfoques, a continuación se proponen posibles rasgos distintivos de los turistas residenciales de Malinalco. Estos serían una mezcla entre lo que pueden significar sociológicamente sus imaginarios, percepciones o comportamientos; lo que ellos imaginan de sí mismos, y lo que los autores imaginamos de ellos. 


\section{Resultados y discusión}

\section{Nostalgia, haciendas, colonialidad}

En Lowenthal (1998), el pasado es como un país extraño, porque el ayer, "a salvo en imaginativas reconstrucciones queda para siempre al margen de nosotros; tan solo hemos atenuado los recuerdos y las crónicas fragmentarias (...) y lo único que podemos hacer es soñar con escapar de los confines del presente” (p. 28). Por una nostalgia generalizada, ese pasado se convierte en tema de mercado, y las asociaciones íntimas ayudan a venderlo, como el anuncio que ofrece "Tu pueblo, tu ciudad, tus raíces... tu propio y personal pedazo de nostalgia" (p. 32). Si la fascinación del paisaje se vincula a una "retórica de la pérdida" (Minca, 2008, p. 224), la nostalgia revela parte de la percepción de los turistas residenciales, porque aunque está ligada a aspectos físicos, requiere elementos -como las asociaciones íntimaspara que el paisaje sea atractivo. Para Lynch (1990), siempre hay algo más de lo que puede ver el ojo y escuchar el oído, pues ningún escenario es experimentado por sí mismo, sino en relación a lo que lo rodea, a los eventos y experiencias precedentes; de aquí, los paisajes poseen legibilidad como patrón de símbolos reconocibles, y son representables (imageability ${ }^{1}$ ) al funcionar como "vastos sistemas mnemotécnicos" (pp. 1-8 y 126).

Legibilidad e imageability refieren la percepción del mundo a través de la subjetividad, aludiendo al imaginario personal o colectivo (Hiernaux, Cordero \& Duynen, 2002). En medio del capitalismo moderno / posmoderno y sus valores occidentales, la fascinación y la pérdida en relación con los paisajes caben en los imaginarios de rechazo (estrés e inseguridad en las metrópolis) y de deseo (paraíso perdido, simpatía por el nativo sano, cohesión familiar, ausencia de presiones), construidos desde cuatro idearios: la conquista de la felicidad, el deseo de evasión, el descubrimiento del otro y el regreso a la naturaleza (Hiernaux, 2010b; Hiernaux et al., 2002).

Para los autores, de clase media y que vamos en fines de semana, Malinalco tiene encantos muy especiales. En nuestros recuerdos, su ambiente apacible se acompaña del sol de mediodía; del aire fresco y húmedo de su placita; de los vendedores de artesanías, pan, tortillas, verdura, fruta, plantas medicinales, nieve. Por la tarde, las imágenes mentales van de los antojitos callejeros al lujo ocasional de un restaurante; y al anochecer se apetece pasar a una cenaduría, o tomar café o una bebida en el pueblo, pero un gran deleite es simplemente caminar por los callejones para respirar su aire antiguo, imaginando un ambiente espacial y temporal totalmente diferente al ordinario, y disfrutando sus olores, colores, texturas (figura 2). En un estilo de vida alejado de ecosistemas "estables", buscamos lo rural y lo poco alterado: una nostalgia que contrasta con el distanciamiento emocional de nuestro lugar de residencia, por el tráfico, el apremio, el caos urbano, el aire contaminado, las perversiones.

Es muy probable que estos imaginarios y percepciones disten sensiblemente de los de turistas residenciales, porque aunque seguramente muchos también leen un contraste entre lo urbano y rural -proviniendo de grandes ciudades que ya expresan

1 Imageability no tiene traducción al español, por lo que aquí se interpreta cercano a la cualidad de ser "representable". 
las problemáticas urbanas contemporáneas-, llegaron con el club de golf (y desde entonces) compraron y siguen comprando grandes terrenos, pagando "precios irrisorios a gente que en ese momento no sabía el valor de la tierra” (P2), y poseen costosas viviendas ajardinadas, bardeadas y vigiladas (figura 3). ${ }^{2}$ Así, pues, y como sucede en muchos lugares, estamos ante una conversión de lo rural en espacio de consumo, moldeada por el espacio hegemónico (Posada, 1999), y demandada por urbanitas que experimentan estilos de vida próximos a los del mundo occidental.

\section{FIgUra 2 | Plaza central de Malinalco}

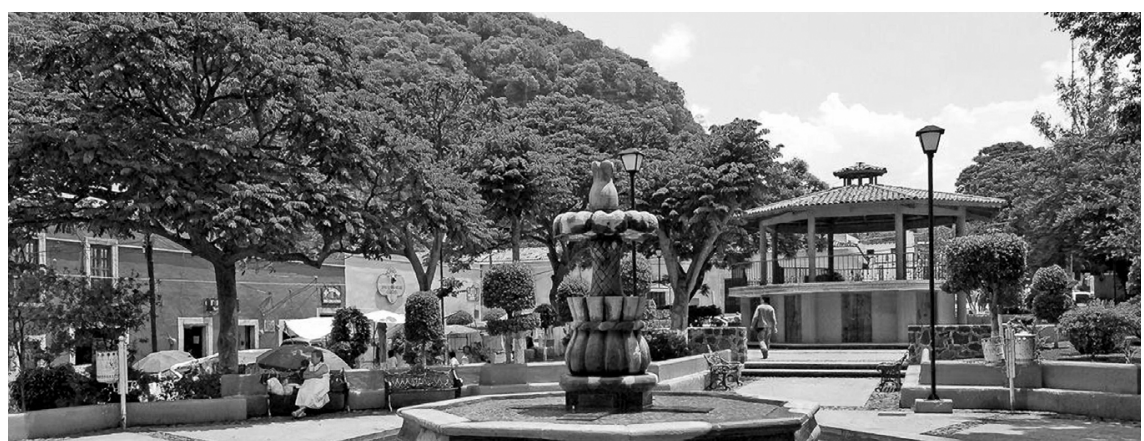

FUENTE FOTOGRAFÍA DE I. GUEVARA. HTTP://WWW.MEXICODESCONOCIDO.COM.MX/MALINALCOPUEBLOS-MAGICOS-DE-MEXICO.HTM

FIGURA 3 | Dos fachadas de residencias
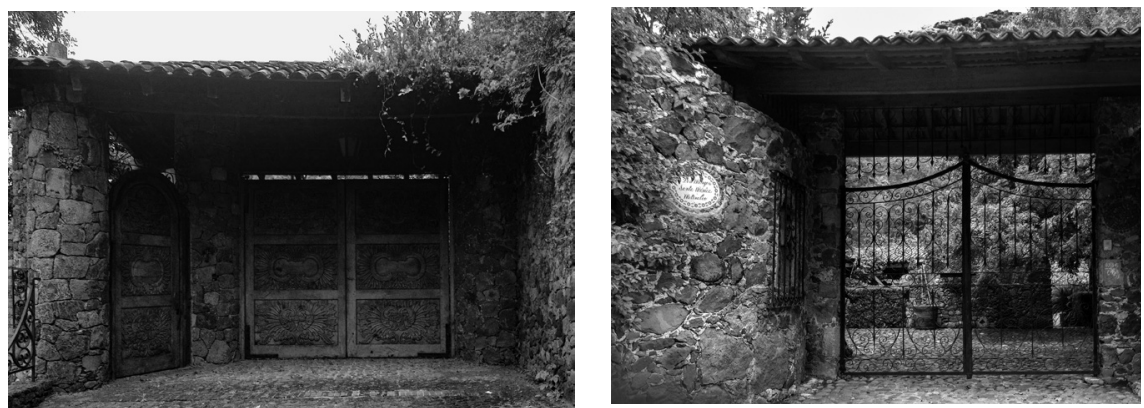

FUENTE FOTOGRAFÍA DE LOS AUTORES, 20 I 4

Siendo así, para los turistas residenciales el paisaje natural y cultural malinalquense concentra la representación de lo deseable asociado a una evasión y a una posición social. Pero también es muy posible que muchos remembren otras épocas en forma muy específica, pues resulta bien significativo que gusten de las haciendas, como en el caso de un comprador que llegó buscando una hacienda y no la encontró, y entonces "la hizo (...), una propiedad inmensa" (P2). Conviene, entonces, recordar un poco la historia al respecto.

2 No fue posible obtener fotografías de los interiores de las residencias. Véanse ejemplos entre las que se ofrecen a la venta, en: http://casas.trovit.com.mx/casa-malinalco 
Las haciendas eran enormes terrenos con casonas señoriales y multitud de espacios y habitaciones. Surgieron en el siglo XvII para satisfacer la demanda agropecuaria de los mercados urbano y minero que no cubrían los pueblos indios, y fueron las unidades productivas predominantes en el campo mexicano entre 1640 y 1940 (Leal, 1986, pp. 5-6). La hacienda moderna -a diferencia del latifundio tradicional, que desapareció después de 1880-1890- participó ágilmente en el crecimiento económico nacional (Meyer, 1986), y entre 1877 y 1911 tendía a concentrar la tierra y sus propietarios estaban en la cúspide de la pirámide social (Speckman, 2008). Al adaptarse al desarrollo industrial, su apariencia varió y algunas se convirtieron en fincas modernizadas; hoy persisten cascos que impresionan por su majestuosidad como símbolos de prestigio (Ponce, 2010, p. 66).

En las haciendas trabajaban peones, administradores, mayordomos, artesanos, carreros. Los hacendados exitosos lograron títulos por sus hazañas, o por relacionarse con la minería, agricultura y comercio; eran de moral y costumbres conservadoras y "señoreaban" sus dominios; sus comportamientos incluían asistencia, solidaridad, paternalismo, prestaciones materiales y simbólicas para el trabajador; y servicio, lealtad y obediencia del último (Ponce, 2010). Una estrategia de fortalecimiento social, cultural y económico, consistía en formar matrimonios entre familias de hacendados (Speckman, 2008). Según Zárate (2005), en la Nueva España muchos hacendados demostraban su riqueza construyendo verdaderos palacios, con decorados que ratificaban su distinción; tiempo después sus casas se hicieron más cómodas y lujosas, con alfombras, candelabros, vajillas, a veces de importación (Ponce, 2010).

Considerando estos datos, la arquitectura y superficie que ocupaban y ocupan las haciendas seguramente representan renombre, estatus, poder económico o influencia social para sus poseedores o aspirantes, en cuyo caso esos significados se arrastran desde hace mucho tiempo. La idea sería que si nuestras imágenes del mundo están compuestas de experiencia personal, aprendizaje, imaginación y memoria (Lowenthal, 1961), lo que se reconoce mentalmente como "hacienda" es un conjunto de atributos inteligible por alguna(s) de esas opciones.

Así lo sugieren varias situaciones. En primer lugar, comprar "fincas que resultan insultantes, por el contraste entre quien tiene todo y quien no tiene nada, es una agresión, un despliegue de verdadero poder" (P2). Un caso es el de un gran inversionista en el sector energético y petrolero -vinculado a un famoso mafioso- que compró una hacienda y cercó su capilla, evitando que el pueblo la utilizara. Dijo: "La hacienda es mía, se van al demonio". Como esto le trajera agresiones de la gente, llevó a un grupo de abogados y 14 guardaespaldas para hacerle frente, lo que no le resultó. Finalmente dijo: "Yo ya no quiero tener nada que ver con estos indios"; se fue y puso en venta la hacienda (D2obs).

Otro caso es el de un hombre ligado a un expresidente e involucrado en grandes negocios. Quiso despojar a un barrio de un manantial, compró una propiedad y se extendió; dijo a la gente: "Quiero unificar mi propiedad, les voy a dejar la calle bien bonita y me quedo con el manantial” (D2obs). La gente contestó: "No le tenemos 
miedo, vamos a luchar, o porque nos ve huarachudos, ${ }^{3}$ piensa que nos vamos a dejar (...) todos tenemos valor, somos bravos" (Nieto 2005, p. 303). La inclinación a la autocomplacencia y la influencia social se revelan en otro relato sobre el consuegro de otro expresidente que para la boda de los hijos construyó su propia capilla, y el día de la boda "no se podía entrar a Malinalco, porque estaban las camionetas de guaruras ${ }^{4}$ de todos los políticos que asistieron" (PI).

Otro personaje, situado en las altas esferas del poder empresarial mexicano, compró una propiedad frente a una capilla. Estando ahí, el día de la fiesta del pueblo -cuando se lanzan cohetes durante días- este seńor mandó decir a los mayordomos ${ }^{5}$ de la iglesia que por favor dejaran de echar cohetes, porque él "viene a descansar a Malinalco". Alguien comentó: "Cómo ves a este, que dejemos de echar cohetes porque está durmiendo; si no le gusta, que se vaya” (D2obs).

Desde la percepción de los autores, estas narraciones evidencian un imaginario de poder y dominio basado en el discernimiento de una posición privilegiada, que se disfruta probablemente por herencia, por dos razones. Primera, los dos factores que detonaron la llegada de los turistas residenciales fueron "la cercanía con la Ciudad de México de un lugar prácticamente virgen, y su condición de marginalidad, lo que resultó muy atractivo, porque de algún modo podrían llegar a hacer lo que querían" (p2). Si esto es así, la marginalidad representa la factibilidad de ejercer una superioridad social, como tratar a los empleados domésticos como "criados", o demandarles tareas indignas (Ramírez \& Osorio, 2013). Aunque "criado, da" es definido por la RAE (2015) como "persona que sirve por un salario, y especialmente la que se emplea en el servicio doméstico", tal término está hoy en desuso; su aplicación parece un atavismo, pues la palabra se ocupaba en la época colonial y describe lo más bajo de la escala social en la población indígena empleada en los hogares espańoles (Lentz, 2010). Y segunda, la creencia de superioridad puede encerrar recuerdos. Observando los orígenes de la burguesía mexicana (Ramírez, 2012; Rosenzweig, 1965), es posible que las memorias de los turistas residenciales estén unidas de manera muy concreta a sus historias familiares, pues pertenecen a clases poderosas económica, social y políticamente en el entorno nacional, cuyos antecedentes tal vez se remontan a la época colonial.

De aquí, suponemos que el paisaje malinalquense ofrece a los turistas residenciales un escenario para la remembranza, como sedimento exteriorizado del pasado; mientras su imagen resulta de la experiencia pasada, incorpora la propia historia (Boulding, 1959). Un suceso que demuestra que Malinalco no siempre tiene esa resonancia, es el de un propietario que construyó una residencia estilo colonial, con alberca, jacuzzi; la amuebló con antigüedades y arregló su gran jardín con plantas exóticas; era el regalo de cumpleaños de su esposa, pero cuando ella la vio, dijo: "La

Huarache: del tarasco kuarache: especie de sandalia tosca de cuero que usaban los indígenas en México (Real Academia Espańola [RAE], 2015).

4 Guarura: Guardaespaldas (Academia Mexicana de la Lengua [AML], 2015).

5 En pueblos de México, se refiere a los encargados de organizar las fiestas en honor de Santos Patronos o con otros cargos específicos. 
casa está muy bien, pero es una zona muy pobre, yo no quiero vivir aquí. A ver si la vendes" (D2obs).

Otra característica que notamos en los relatos es cierta ingenuidad de los propietarios, al suponer que los habitantes estarán dispuestos a complacerlos, o al tratar de imponer su voluntad. Tal vez esto se debe a la seguridad de una potestad, o al desconocimiento de que Malinalco no es un pueblo dócil, pues ha mostrado fuerte resistencia a los turistas residenciales y a la invasión de su territorio (Castro \& Ochoa, 2006; Nieto, 2005; Royuela \& Ramírez, 2015). En otros casos, los propietarios parecen francamente prepotentes, posiblemente por las mismas razones.

Otra narración que revela afán de domino se refiere a uno de los empresarios más poderosos de México ${ }^{6}$ que adquirió 800 hectáreas en el municipio, después de comprar la hacienda que dejó el inversionista mencionado. Alguien comentó: "Llegaron abogados del señor que acaba de comprar la propiedad, pero nuestro pueblito está en medio (...) y este señor quiere hacer un lugar para muchas residencias en el bosque (...) nos dijeron que nuestro pueblito no se va a ver bien en medio de todo eso, entonces que nos compra el pueblito ¡Cómo! ¿Cuándo se ha oído eso? Nosotros dijimos que no podemos vender, aquí está nuestro ombligo enterrado, nuestros muertitos" (PI).

Esto demuestra la voracidad del personaje, "que está comprando todo el sur del valle de Malinalco", y "la gente se está teniendo que deshacer de sus tierras; aunque no tienen a donde ir" (P2); de hecho, "los está expulsando" (PI). Pero es importante resaltar que, además de suelo, se adquiere una hacienda como residencia, pues eso significa un patrón sociológico, todo un estilo de vida, un habitus que conecta al propietario con determinadas inversiones. La importancia de ese estilo de vida es que, más allá de los deseos, pasiones y afectividades que encarnan en los sujetos sociales, expresa los proyectos políticos que lo configuran (Palacios, García \& Rico, 2013). Por lo tanto, un vehículo de la transformación de Malinalco como proyecto político es, curiosamente, un imaginario que contiene a "la hacienda".

Ese imaginario -ya como parte de una reorganización territorial- hace mucho más que remembrar, al encontrar cabida en cierto orden de cosas, y entonces el estilo de vida denota la inserción socioeconómica. Puesto que ese estilo y las preferencias personales están lejos de ser autónomos, delatan una actualidad que reclama prácticas determinadas para sostener y continuar el proyecto en cuestión, ya que los imaginarios son prescriptivos, producen paisajes (Graburn \& Gravari, 2011). Hablamos de una representación que no procede de puras fantasías o recuerdos, sino de un posicionamiento social interiorizado y relacionado con una tradición, pero solo si esta probó eficacia en otros tiempos, y solo si en la actualidad es útil para reiterarlo.

En esta línea, resultan llamativas algunas prácticas de los turistas residenciales que recuerdan costumbres de las clases pudientes desde la época colonial, como realizar las actividades principales en la Ciudad de México y pasar en Malinalco solo algunos fines de semana, o formar matrimonios entre ciertas familias. Su relación con expresidentes (no en pocos casos) también es interesante, pues manifiesta un 
perfil de actores cuya vigencia en el actual orden económico y social depende de su habilidad negociadora y de vinculación con los círculos políticos y de alta sociedad.

Tras estas reflexiones se encuentra la idea de una memoria colectiva entre los propietarios referidos, cuya fuerza alude a los poderes presentes, conduciendo y renovando una conciencia grupal y dando continuidad al pasado y dirección al futuro. Esto sería así, porque "las rutinas y vestigios del pasado requieren cierto automatismo colectivo"; porque la imagen que un grupo tiene del ambiente que lo rodea y de su relación con él, "es fundamental para la idea que el grupo tiene de sí mismo"; y porque "cada etapa del desarrollo de un grupo, puede traducirse a términos espaciales" (Halbwachs 2004, pp. 131 y ss.).

Pese a las resistencias puntuales de los habitantes, el orden de cosas actual tendrá continuidad en la medida en que despliegue anclas en el territorio. Es el caso del empleo, porque con ello se logra, en ciertos casos, el consentimiento de la población para los propietarios y sus actividades: prácticamente todos nuestros entrevistados reconocen su importancia para su economía familiar, como empleados del segmento en la construcción y luego como vigilantes, servidores domésticos, jardineros, cocineras; otros en comercios u otros giros que los atienden, y estos empleos se han convertido en un recurso para la población; "es una forma de control" (PI; P2; P3).

Gracias a investigaciones en España, sabemos que el fenómeno se acompaña de un discurso que conduce a los pobladores a pensar que su única posibilidad de progreso pasa por el modelo residencial (Mantecón, 2008); el empleo es, entonces, un mecanismo que inscribe en el espacio su capacidad reestructuradora económica, espacial y simbólica. Así -y pese a que este modelo progresa en territorios con exclusión histórica- se logra la inserción de la población en él, en un proceso que, en una suerte de tendencia crónica, sería una verdadera colonialidad que naturaliza "concepciones sobre la modernidad y el progreso" y subalterniza a sus poblaciones y modos de vida (Palacios et al., 2013, p. 183).

\section{Hombres de éxito, racialización}

Los propietarios de haciendas son un subsegmento de los turistas residenciales. En forma más general: "No es el retiro ni la jubilación (...) sino roles económicos; es decir, 'a mí me sobra el dinero y quiero descansar o pasar los fines de semana (...) tener una especie de prestigio' (...) es causado por la metrópoli, el estatus laboral, el esnob". Y "hay mucha gente que viene por ser lugar de moda, por ser parte de la elite" (Р3). En cuanto al desarrollo inmobiliario Club de Golf, alguien opinó: "Es una especie de concurso; si [se] quiere mostrar que hay con qué, la casa tiene que ser de alguna firma de arquitectos prestigiada (...) casi casa de revista, porque no puede ser menos que las de al lado". "Es una burbuja que ha mantenido a muchos en el anonimato", pues "esta gente por lo general no baja al pueblo" (D2obs; PI). Además, "hay una sección llamada 'El Pueblito' en donde hay casas que parecen de pueblito, pero nice". Y un caballerango (de caballos pura sangre) habla de "un importante empresario que iba dos o tres veces por semana a jugar golf, pero para eso toma su helicóptero, aterriza en el club, juega, come y toma el helicóptero de regreso, porque están medio feos los caminos y no quiere arriesgarse" (D2obs). 
Puede así distinguirse un amplio grupo de acaudalados nacionales -que no excluye propietarios de haciendas- del medio empresarial, financiero o político, identificables por la adquisición de símbolos materiales de distinción, que consideran importante mostrarse como parte del estrecho grupo nacional e internacional que sortea las crisis económicas y participa en la mundialización como elites (Hiernaux 2010c, p. 112). Tal vez algunos se imaginan como hombres de "éxito", que "merecen" darse ciertos gustos, y quedarían descritos por Bourdieu como industriales y gente dedicada a actividades comerciales: con abundante capital económico y escaso cultural, que gustan de las segundas residencias, vacaciones en hoteles, comidas de negocios, automóviles extranjeros, tenis, golf, subastas y galerías de arte convencionales (Featherstone, 1985).

Relacionando poder y actividades cuestionables, muchos no encumbrados por tradición encajarían también en categorías como burguesías enriquecidas del petróleo, de la industria, actividades terciarias, o "neorricos" (mafias, comercio ilegal, tráfico de personas, estupefacientes) (Hiernaux 2010a, p. 14). Si estos sujetos son actores en redes de poder, están acreditados en procesos económicos y políticos del país y más allá, y su estilo de vida incluiría flexibilidad y movilidad por variedad de espacios, contextos y experiencias. El ámbito y cultura globales de los contextos citadinos satisfacen ese estilo en cuanto a transacciones y comunicación, pues muchos tienen importantes nexos nacionales e internacionales. Dicha cultura comprendería procesos transnacionales (Featherstone, 1997).

Con el desarraigo que supone lo anterior, imaginamos un desprendimiento del lugar de residencia, si este perdió su profundidad histórica e identitaria, y la multirresidencia como signo de pertenencias e identidades múltiples o fragmentadas (Hiernaux 2010b, p. 28). Entre estas pertenencias, Malinalco satisface parte del estilo de vida relacionado con tranquilidad, privacidad, naturaleza, recreos imitados de Europa, o una rusticidad elegante, pues a algunos les encanta su combinación entre naturaleza, historia y cultura (Ramírez \& Osorio, 2010). Como consumidores modernos, estos individuos presentan consumo guiado por la clase social como prescripción, y ostentación para compararse, igualar o superar a quienes están por encima (Veblen); moda como producto de la distinción de clase, lo superfluo, lo alejado de la significación práctica (Simmel); "estilización de la vida" (Weber); expansión del consumo como libertad individual (Featherstone) (López, 2004).

Estos turistas residenciales también se acercan al consumidor posmoderno, aquel cuya identidad "se funde en el consumo", dejando que "las mercancías le hablen" y" expongan sus estilos"; individuo estimulado para adquirir las novedades y crearse una "identidad autónoma" (Ragnedda, 2008, p. 8). O individuos que construyen su identidad a través del valor intangible, simbólico o cultural del consumo, aunque los estilos de vida en que se desenvuelven se acompañen de sistemas de valores altamente incompatibles entre sí (Berner \& Van Tonder, 2003). 


\section{FIgURA 4 | Ubicación de las segundas residencias en Malinalco, Estado de} México, 2014

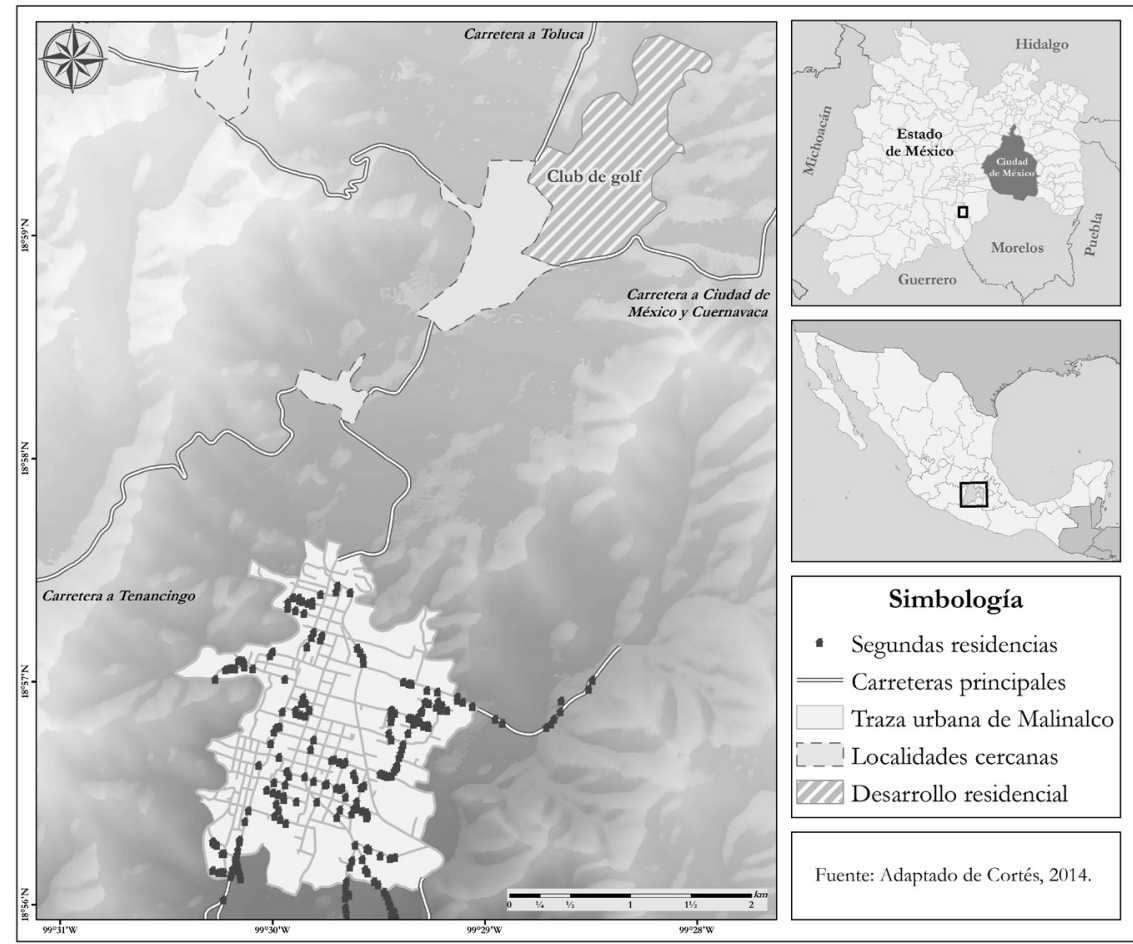

FUENTE ADAPTADO DE CORTÉS, 20 I 4

Todas estas características se traducen en numerosas transformaciones socioespaciales. Como se observa en la figura 4, los turistas residenciales se ubican en todo el poblado, además de en el desarrollo inmobiliario Club de Golf, contribuyendo a la urbanización y a la conurbación, pues Malinalco está entre los municipios con urbanización superior al promedio de su región, la cual, por otra parte, se ha ido especializando en servicios turísticos y recreativos, mientras sus dinámicas demográfica, urbanística, de modernización y de terciarización se relacionan directamente con la megalópolis del Centro del País (Gobierno del Estado de México, 2012, pp. 32-44). Este desenvolvimiento se caracteriza por especulación inmobiliaria, búsqueda de la calidad paisajística, elitización, exclusión, pero cómodamente: sin una renuncia a las comodidades de la vida urbana, congruente con la armonía, tranquilidad y disfrute del paisaje que supuestamente se revalora (Hidalgo, Arenas \& Santana, 2016). Considérese además lo siguiente.

Le estimo a esa casa millones de dólares porque está enorme (...) construida en un lugar donde se encontraron algunas de las ocupaciones del periodo preclásico y clásico más complejas de la zona. Cuando trabajaba en el INAH [Instituto Nacional de Antropología e Historia], llegó un tipo y empezó a construir su casa. Me llamaron 
(...) y me dijeron que había una denuncia: había excavado los cimientos sobre la plataforma y no avisó; había hecho la cisterna y en el corte estaba una sucesión de pisos de estuco de la época prehispánica, así que le clausuré (...) se enfureció y vino a las oficinas, empezó a pegar de gritos, le dijeron que no se podía. A la semana recibí una llamada de mi jefe diciendo: "La instrucción es que lo liberes, hablaron de la Presidencia de la República, al señor se le va a permitir construir". Les dije que yo no iba a firmar la destrucción de la herencia cultural, pero más adelante continuaron con la casa (...). Otra persona que también tiene una propiedad en un lugar con vestigios arqueológicos, excavó hasta roca madre y ahí construyó una cava”. (P2)

De la narración interpretamos que aunque para ambos personajes la "herencia cultural" no representa un obstáculo a sus deseos, el primero acredita competencia para modificar el espacio físico y derribar los símbolos locales o nacionales: una legitimidad en los dominios del poder nacional. Otros individuos con esa prerrogativa, reconocidos como "iniciativa privada" o "grupos de poder", han intervenido en los cambios de uso del suelo, obras públicas, energía eléctrica y acreditación de servicios turísticos y de "Pueblos Mágicos" (P3).

La influencia de los turistas residenciales también implica la desaparición de todo lo que era "parte de la vida del pueblo antes del club de golf: mayordomías, convivencia comunitaria, hierbas medicinales, el cuajinicuil, ${ }^{7}$ la guayaba, el calmil, ${ }^{8}$ la pomarrosa, el maíz y el frijol negro; tienditas [hoy] sustituidas por las que atienden [al] turismo de alto nivel, que demanda spas, masajes, buenos vinos, cosas exóticas" (P3). Además, antes había un acuerdo entre los pobladores de "respetar los caminos y nacimientos de agua como públicos", y "campos abiertos, donde se veía a los animales pastando"; hoy "muchos son [propiedad privada]", "ya no hay espacios para estar con la familia", "hay lugares donde se te imponen las bardotas," [pues] parte de las montańas las hicieron suyas". En tanto, "los terrenos se han encarecido mucho y es injusto tener el mismo gasto que la gente que viene", pues "antes se notaba la diferencia entre los pobladores y los de afuera (...) los vendedores subían el precio del pan a los de afuera, pero a nosotros no"; "en cambio ahora ya es parejo para todos, y no se reconoce a los pobladores" (PI).

En todo esto, tiene gran importancia la presión -de turistas residenciales y políticos- sobre los propietarios de terrenos agrícolas y huertas "para que los vendan, pues intentan sacarlos a toda costa” ( 13 ). Por ello, el modelo turístico residencial avanza a grandes pasos y también a través de pequeńas transformaciones económicas y socioculturales: valorización del suelo, éxodo rural, mercantilización de la vida cotidiana, fractura de las costumbres y redes socioeconómicas tradicionales (figura 5).

En cierta ocasión (Diobs), en un comercio de arte en el que se exhibían esculturas muy grandes y hermosas con temas budistas, al preguntar de dónde eran, la dueña comentó:

7 Fruto en vaina con pulpa dulce. Del náhuatl cuauhxonecuilli: árbol mimosáceo (RAE, 2015).

8 Milpa (cultivo de maíz y otras especies asociadas) ubicada junto a la casa (AML, 2015).

9 El entrevistado usa "bardota" como aumentativo de barda. 
Son de Timor, un lugar de Indonesia. Mi esposo y yo las compramos por lo bellas que son y para ayudar a la gente. Estaban logrando su independencia, y [sin] dinero para nada (...) su arte y sus objetos los ofrecían a los turistas, muebles, telas y todo (...). Las trajimos en un contenedor (...). Mi esposo sale constantemente a comprar arte, ahora está en unas islas de Italia. (...) Viene mucha gente importante [Un empresario muy poderoso en México] es uno de mis clientes. Un negocio que quiera prosperar debe tener arte de Indonesia, Pakistán e India. Si no (...) fracasa. Claro que también tenemos cosas de Bali, China.

FIGURA 5 Don Efrén Maldonado, último malinalquense que vistió a la usanza antigua, frente a una residencia

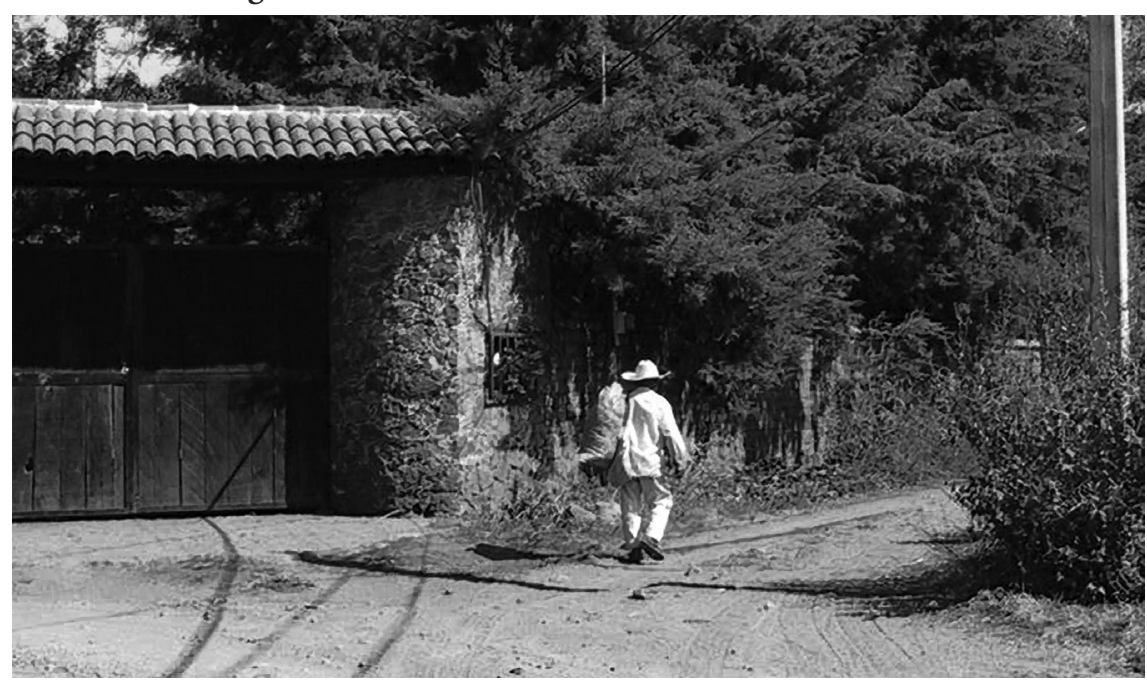

FUENTE FOTOGRAFÍA DE LOS AUTORES, 2004

En esta narración resalta el potencial de las artes subalternas para representar opulencia o refinamiento en cierto imaginario. Pero este último revela también una ausencia significativa de conflictos entre la construcción de una residencia o la adquisición de arte extranjero, y el acervo cultural local; o entre la tenencia del suelo por citadinos, y el carácter rústico del poblado. En todo caso, las acciones y omisiones de los turistas residenciales dan cuenta de una aprehensión del ambiente que transita entre sistemas de valores (tal vez) incompatibles, y favorece todo tipo de conexiones entre escalas geográficas. Desde la percepción de clase media de los autores, la instrumentalidad del espacio derivada representa un riesgo destructivo para los recursos locales o nacionales, y es incompatible con nuestro imaginario, en el que "las raíces", "el territorio", el "patrimonio nacional" o "lo local" tienen mayor fuerza.

Tema colindante es el de "los indios". Un relato adicional se refiere a una figura de la televisión comercial: "El tipo es famoso y las jovencitas estaban fascinadas con él. Intentaron que les (...) firmara un autógrafo y él dijo 'yo no quiero nada con estos indios, que no me molesten, yo vengo aquí a descansar'. La gente estaba 
enojadísima” (P2). Esta actitud expresa racialización: diferenciación ideológica con cargas de sentido atribuidas a la apariencia física, cuyas raíces están en la historia de Latinoamérica, y que apuntaló la división de clases y la exclusión (Margulis, 1999). En el contexto descrito, disposiciones como esta reflejan las creencias acompañantes de los roles y su funcionalidad, independientemente de las aspiraciones de libertad o fama. Para ello, el prestigio o éxito social se cifran en códigos y estereotipos que establecen normas de admisión y descalificación para lograr la afirmación del yo y de la clase social, lo cual constituye una finalidad personal detrás de la diferenciación, y un aspecto de su propio condicionamiento social.

Por lo anterior, resulta interesante que los acaudalados deseen diferenciarse entre sí. Para quienes conocemos el ambiente político y económico en México, y desde nuestra lectura de las percepciones de los turistas residenciales de Malinalco, parece posible que pretendan diferenciarse no tanto en términos de abolengo o aristocracia, sino en los del poder de una estirpe logrado a base de relaciones estratégicas. Quizá este logro exige refrendar y renovar la vigencia en ese ambiente, entre otras cosas, a través de demostrar un cierto grado de consumo frente a los homólogos; es decir, probando capacidad para mantenerse en el medio, sostener y acrecentar las fortunas. Con esta interpretación, la expresión de que se quiere "mostrar que hay con qué" nos resulta plenamente inteligible.

\section{Capital cultural y aislamiento}

Otros turistas residenciales están afiliados a la Fundación Comunitaria Malinalco (FCM) y a Imaginalco, organizaciones que comparten miembros. La misión de la primera es "fomentar la participación ciudadana para preservar, mejorar y regenerar el entorno social y ambiental de Malinalco, a través de la formación, vinculación, financiamiento y fortalecimiento de capacidades colectivas organizadas, propositivas y responsables". Los objetivos de la segunda son "ofrecer a los jóvenes del barrio de San Martín (...) en riesgo o involucrados en relaciones violentas o adicciones, opciones para construir una vida sana y sin violencia" y "articular los esfuerzos de diferentes actores sociales para contribuir a la construcción de un Malinalco más seguro y con menor propensión a la violencia”. Se afirman sin fines lucrativos, reciben donaciones, y algunos de sus asociados se relacionan con los negocios inmobiliarios y los servicios turísticos. Los entrevistados dicen que llegaron "en buen plan"; "realizan separación de basura y jornadas de reforestación"; "no tienen con ellos [los residentes originarios] más convivencia que el trabajo doméstico"; "tienen solvencia económica"; "buscan hacer algo por la comunidad, quieren apoyar"; "hacen convocatorias para la seguridad y cosas ambientales", y que se diferencian de los de Club de Golf, porque "estos solo llegan y se encierran" (PI).

Por lo anterior, el habitus de este subsegmento podría corresponder al de la "nueva clase media" que delinea Featherstone (1997) continuando los estudios de Bourdieu: ascendiendo numérica y socialmente, son intermediarios culturales clave, creadores o transmisores de símbolos, legitimadores de estilos de vida; promotores de la estilización -moda, diseño, ocio, deporte, nuevas artes y cultura popular-, incluyendo reciclar lo viejo y buscar lo vanguardista; empresarios que buscan actividades y experiencias, y para quienes la edad y vejez son fuente de ansiedad. Pueden 
también orientarse a deportes de estilo e individualismo (ala delta), poseer buen capital cultural y bajo económico, e inclinarse a la bohemia, festivales de vanguardia, lenguas extranjeras, mercado de pulgas, ecología, campamentos, caminatas en el campo. Esforzándose por mantenerse activos o planeando el retiro, pueden involucrarse en la educación, y algunos prefieren un ocio austero o prácticas culturales más serias; en ese sentido, comparten con los intelectuales una estética ascética, rechazando materialismo y lujo. El segmento incluye mujeres que construyen su propio habitus para su estilo de vida, o que ingresan al mercado laboral ya liberadas de las responsabilidades familiares (Featherstone, 1997, pp. 127-136).

De esta descripción, imaginamos que estos sujetos se piensan a sí mismos como reformadores que van con los reclamos de la época "por la comunidad", "la convivencia" o "el desarrollo sostenible"; o como portadores de originalidad, de los cambios precisos, los valores perdidos u oportunos para la regeneración social y ambiental, el deseo de "superación". Sin imaginar que su presencia pudiera ser incompatible con el mantenimiento de los recursos (pues se asumen residentes), es posible que se atribuyan la misión de divulgar los paradigmas correctos. Por las imágenes que difunden (Fundación Comunitaria Malinalco, s.f; Imaginalco, s.f), posiblemente tienen aceptación de los habitantes o incluso seguidores. Tal vez cuentan con lo que Bourdieu llamó la "buena fe" y toda una estrategia para obtener prestigio mediante donaciones y favores, que, sin embargo, no carece de una lógica económica (Fernández, 2013). De ser así, esa estrategia también afianza el modelo residencial, pero depende de la valoración de los pobladores a largo plazo, pues implica transformaciones territoriales.

Finalmente, un individuo que "es el dueño de una propiedad inmensa que está escondida hacia atrás (...) parece un jardín municipal (...) tiene una actitud diferente, se ha acercado mucho al Museo Luis Mario Schneider y ha donado objetos (...). Tiene mucho dinero, pero cuando llega acá, no llama la atención (...) es de perfil bajo, él no ha agredido a la gente con su actitud, ha sido bastante prudente" (P2). Sin duda, pertenece al subsegmento de los intelectuales y tiene rasgos en común con el anterior. Pese a formar parte del mismo modelo y seguramente de círculos influyentes, de la narración imaginamos que es atraído a Malinalco por su cultura y tradición, por el ritmo de la vida o la belleza escénica, más que por la demostración de poder o capacidad adquisitiva. En contraste con quienes buscan ostentar, o la privacidad por ser personajes públicos, tal vez en este caso se trate del simple distanciamiento de la ciudad para el reencuentro consigo mismo, del gusto por el aislamiento.

Esto nos recuerda otras sensaciones que se experimentan en Malinalco: ¿’Por qué y para qué requerimos aislarnos? Tal vez atraídos por los significados de una isla. Las islas como mundos miniatura aparentemente autocontenidos y criaderos de la imaginación; lugares remotos como metáforas eidéticas para la identidad: el universo-isla, el planeta-isla, el ser-isla, pues -como nosotros- las islas son entidades finitas que recuerdan el estado solitario de la Tierra, la soledad de las estrellas y galaxias. La isla, como la condición humana, alterna el apego con la liberación, y cada uno al mismo tiempo es conscientemente individual y está abandonado en la autoconciencia, siendo solo yo y nadie más, pero inseparablemente atado a los ancestros y descendientes (Lowenthal, 2007). 


\section{Conclusiones}

En este estudio hay una aproximación a aspectos subjetivos de los turistas residenciales de Malinalco, con base en un enfoque epistemológico y metodológico que realza su importancia en las transformaciones socioespaciales. La interpretación que hacen los autores respecto de las percepciones, creencias e imaginarios de esos turistas es inherentemente crítica, pues son leídos desde un habitus académico y de clase media. Este incluye una mayor afinidad histórica, política, social, económica y cultural con los actores locales y, por lo tanto, con las voces menos tomadas en cuenta en las políticas nacionales.

En esa lectura, se intentó delinear intereses, estrategias, prácticas y mecanismos de anclaje socioeconómico y simbólico del turismo residencial. Con ello se quiso denunciar la instrumentalización del paisaje malinalquense que conduce a la expansión inmobiliaria, gracias a actores con poder económico, político y simbólico, que incrustan en el lugar el influjo de la modernidad y posmodernidad, y van formando sus periferias. La inclusión de los aspectos subjetivos de esos actores supone un giro interpretativo que difícilmente afloraría en un estudio cuantitativo, y que enlaza las posiciones sociales y experiencias personales y colectivas con la materialización de nuevos ambientes.

Aun cuando la reflexión realizada conlleva sesgos debidos a la perspectiva de los autores, descubre un conjunto posible de fuerzas presentes en las transformaciones, fuerzas de grupos sociales que interpretamos y con los cuales nos comunicamos desde nuestras subjetividades. La comprensión de esas fuerzas y grupos, si no ha de estancar el conocimiento, no tendría que recurrir a los paradigmas de siempre, ni a la admisión de sucesos "externos" a nosotros mismos, ni al supuesto de que somos autónomos y carecemos de responsabilidad sobre las consecuencias de nuestros actos. En este sentido, aquí se sugiere una continua reconceptualización y reinterpretación de los fenómenos territoriales, proponiendo el estudio de sujetos integrales que interactúan con naturaleza y cultura. De esta visión a nuestras interioridades y a las de los demás podríamos esperar un mayor compromiso ético y político con los menos favorecidos, y una visión más crítica hacia los entramados de poder que condicionan nuestras percepciones e imaginarios.

El escrito se centra en residentes metropolitanos física y simbólicamente de algún modo cercanos a Malinalco, que se establecen y realizan sus actividades, mientras manifiestan y defienden sus roles y estatus, su habitus. Éste último, revelado por su comportamiento en el contexto específico, impulsa a la inclusión en cierto perfil de actores y consumidores, pero, al mismo tiempo, a la diferenciación en torno a las posesiones, el derroche, el vanguardismo. En lo que concierne al estrato socioeconómico más elevado, puede decirse que se ha anclado en la colonialidad correspondiente al modelo turístico residencial, con un elemento detonador: la posibilidad de dominio sobre una comunidad de origen indígena y sus recursos.

Esa riqueza se articula con poderes supralocales, evidenciando las redes de desenvolvimiento de sus actores y ligándose inevitablemente al alarde, a la arbitrariedad. Pero aunque muestra la clara faceta de un poder aliado al presente moderno / posmoderno, tiene nítidos tintes tradicionales, pues la palabra "hacienda" no solo 
tiene resonancia, sino también vigencia en la actualidad del pueblo, pasados dos siglos de independencia. Así, los rasgos descritos adoptan el matiz característico del amo superior e inaccesible a la gente común o a la opinión pública, mientras la población queda sometida a una dinámica que, no obstante parecer reciente, encuentra sus raíces en la historia.

La respuesta de la población ante la inserción de los turistas residenciales también evoca rasgos tradicionales. Así, admite ciertas condiciones - con reacciones que van desde el convencimiento a la resignación- o resiste -con rechazo o violencia-, mientras avanza la desestructuración de su mundo tradicional. La confrontación o asimilación entre los pobladores y los turistas residenciales en el territorio seguramente continuará y variará dependiendo de la correlación de fuerzas presentes, pues la batalla por el paisaje es y será por "el control político e ideológico de los significados que asignamos a nuestra relación con el espacio” (Minca, 2008, p. 227).

\section{Referencias bibliográficas}

Academia Mexicana de la Lengua (AML). (2015). Diccionario de mexicanismos. Versión en línea en http://www.academia.org.mx/DiccionarioDeMexicanismos

Ameigeiras, A. (2006). El abordaje etnográfico en la investigación social. En I. Vasilachis (Coord.), Estrategias de investigación cualitativa (pp.107-152). Barcelona: Gedisa.

Ayuntamiento Constitucional de Malinalco (2013). Plan de Desarrollo Municipal de Malinalco 2013-2015, Méx. México: Gobierno del Estado de México. http://bit.ly/2i20EhO

Beligand, N. (1999). Les communautés indiennes de la vallée de Toluca 1480-1810. Tesis de Doctorat de l'École des Hautes Études en Sciences Sociales, Université de Toulouse, Toulouse, Francia.

Berdoulay, V. (2012). El sujeto, el lugar y la mediación del imaginario. En A. Lindón \& D. Hiernaux (Dirs.), Geografias de lo imaginario (pp. 49-65). México: Universidad Autónoma Metropolitana - Anthropos.

Berner, A \& Van Tonder, C. L. (2003). The postmodern consumer: Implications of changing customer expectations for organisation development in service organisations. Journal of Industrial Psychology, 29(3), 1-10. http://sajip.co.za/index.php/sajip/article/ viewFile/117/113

Boulding, K. E. (1959). The image. Ann Arbor, MI: University of Michigan Press.

Bourdieu, P. (1988). La distinción. Criterio y bases sociales del gusto. Madrid: Altea, Taurus, Alfaguara.

Castro, P. \& Ochoa, D. (2006). Malinalco: entre la gentrificación y la resistencia. En X. Noguez (Coord.), Malinalco y sus contornos a través de los tiempos (pp. 193-201). México: Universidad Autónoma del Estado de México El Colegio Mexiquense A. C.

Cortés, I. (2014). Factores de localización de las segundas residencias en la localidad de Malinalco, Estado de México. Tesis de Maestría, Universidad Autónoma del Estado de México, México.

Featherstone, M. (1985). Leisure, symbolic power and the life course. The Sociological Review, 33(S1), 113-138. doi: 10.1111/j.1467-954X.1985.tb03303.x 
Featherstone, M. (1997). Global culture: An introduction. En M. Featherstone (Ed.), Global culture. Nationalism, globalization and modernity (pp. 1-14). Londres: Sage.

Fernández, J. (2013). Capital simbólico, dominación y legitimidad. Las raíces weberianas de la sociología de Pierre Bourdieu. Papers, 98(1), 33-60. doi: http://dx.doi.org/10.5565/ rev/papers/v98n1.342

Fundación Comunitaria Malinalco, A.C. (FCMAC) (s.f). En línea. https://www.malinalco.net/ fundacioncomunitariamalinalco

Gobierno del Estado de México (gem). (2012). Región VI Ixtapan de la Sal. Programa Regional, 2012-2017. México: GEM. https://issuu.com/copladem/docs/region_vi

Graburn, N. \& Gravari, M. (2011). Editors' Introduction. Journal of Tourism and Cultural Change 9(3), 159-166. http://doi.org/10.1080/14766825.2011.640490

Guevara, I. (s/f). [Fotografías] Malinalco. Lugar de la flor del zacate (Estado de México). México Desconocido. http://www.mexicodesconocido.com.mx/malinalco.-lugar-de-laflor-del-zacate-estado-de-mexico.html

Halbwachs, M. (2004). La memoria colectiva. Zaragoza: Prensas Universitarias de Zaragoza.

Hidalgo, R., Arenas, F. \& Santana, D. (2016). ¿¿tópolis o distópolis?: producción inmobiliaria y metropolización en el litoral central de Chile (1992-2012). EURE, 42(126), 27-54. http://doi.org/10.4067/S0250-71612016000200002

Hiernaux, D. (2010a). Las segundas residencias: una zona gris. En D. Hiernaux (Coord.), Las segundas residencias en México: un balance (pp. 13-20). México: Plaza y Valdés.

Hiernaux, D. (2010b). Las segundas residencias: un abordaje geográfico. En D. Hiernaux (Coord.), Las segundas residencias en México: un balance (pp. 21-35). México: Plaza y Valdés.

Hiernaux, D. (2010c). Acapulco: turismo residencial, nuevos espacios y estilos de vida. En D. Hiernaux (Coord.), Las segundas residencias en México: un balance (pp. 99-117). México: Plaza y Valdés.

Hiernaux, D., Cordero, A. \& Duynen, L. (2002). Imaginarios sociales y turismo sostenible. Cuaderno de Ciencias Sociales, 123. Costa Rica: Facultad Latinoamericana de Ciencias Sociales (Flacso-Costa Rica). http://biblioteca.clacso.edu.ar/ar/libros/costar/ cua123.pdf

Huete, R. \& Mantecón, A. (2009). Los límites entre el turismo y la migración residencial. Una tipología. Papers, 95(3), 781-801. http://www.raco.cat/index.php/papers/article/ view/199163/0

Huete, R., Mantecón, A. \& Mazón, T. (2008). ¿De qué hablamos cuando hablamos de turismo residencial? Cuadernos de Turismo (22), 101-121. http://revistas.um.es/turismo/article/ view/48091

Imaginalco (s.f). En línea. http://imaginalco.org/es_ES/

Instituto Nacional para el Federalismo y el Desarrollo Municipal (Inafed) (S.F.). Enciclopedia de los Municipios y Delegaciones de México. Estado de México. Malinalco. En línea. http://www.inafed.gob.mx/work/enciclopedia/EMM15mexico/municipios/15052a. html

Leal, J. (1986). Campesinado, hacienda y Estado en México. Secuencia 05(005), 5-32. doi: http://doi.org/10.18234/secuencia.v0i05.137 
Lentz, M. (2010). Criados, caciques y artesanos. Mayas urbanos de Yucatán a finales del siglo XvıIr. En F. Castro (Coord.), Los indios y las ciudades de Nueva España (pp. 217-236). México: Instituto de Investigaciones Históricas, Universidad Nacional Autónoma de México (UNAM). http://www.historicas.unam.mx/publicaciones/publicadigital/libros/ indiosciudades/indiosciudad010.pdf

Ley, D. (2009). Behavioural Geography. En D. Gregory, R. Johnston, G. Pratt, M. Watts \& S. Whatmore (Eds.). The Dictionary of Human Geography (pp. 44-45). Oxford, uk: John Wiley \& Sons. doi: 10.1093/acref/9780199599868.001.0001

López, M. C. (2004). El análisis sociológico del consumo: una revisión histórica de sus desarrollos teóricos. Sociológica (5), 161-188. http://ruc.udc.es/dspace/bitstream/ handle/2183/2725/SO-5-6.pdf?sequence $=1$

Lowenthal, D. (1961). Geography, experience and imagination towards a Geographical Epistemology. Annals of the Association of American Geographers, 51(3), 241-260. doi: 10.1111/j.1467-8306.1961.tb00377.x

Lowenthal, D. (1975). Past time, present place: Landscape and memory. The Geographical Review 65(1), 1-36. doi: 10.2307/213831

Lowenthal, D. (1998). El pasado es un país extraño. Madrid: Akal.

Lowenthal, D. (2007). Islands. Lovers and others. The Geographical Review, 97(2), 202-229. doi: 10.1111/j.1931-0846.2007.tb00399.x

Lowenthal, D. \& Prince, H. (1964). The English landscape. The Geographical Review, 54(3), 309-346. doi: 10.2307/212656

Lowenthal, D. \& Prince, H. (1965). English landscape tastes. The Geographical Review, 55(2), 186-222. doi: $10.2307 / 212710$

Lynch, K. (1990). The image of the city. Cambridge, ma: The MIT Press.

Mantecón, A. (2008). Actores y relaciones en el sistema turístico residencial. En M. García \& K. Schriewer (Eds.), Ni turistas ni migrantes. Movilidad residencial europea en España (pp. 311-327). Murcia: Isabor.

Margulis, M. (1998). La racialización de las relaciones de clase. En M. Margulis, M. Urresti y otros, La segregación negada. Cultura y discriminación social (pp. 37-62). Buenos Aires: Biblos. https://antrosocial.files.wordpress.com/2013/04/115519864-margulis-laracializacion-de-las-relaciones-de-clase.pdf

Meyer, J. (1986). Haciendas y ranchos, peones y campesinos en el porfiriato. Historia Mexicana, 35(3), 477-509. http://historiamexicana.colmex.mx/index.php/RHM/ article/download/1916/1734

Minca, C. (2008). El sujeto, el paisaje y el juego postmoderno. En J. Nogué (Coord.), El paisaje en la cultura contemporánea (pp. 209-232). Madrid: Biblioteca Nueva.

Nieto, R. (2005). Aguas calientes: ensayo sobre la gentrificación y resistencia en Malinalco. Tesis de Maestría, Universidad Autónoma del Estado de México, México.

Olwig, K. (2003). Landscape: The Lowenthal legacy. Annals of the Association of American Geographers, 93(4), 871-877. doi: 10.1111/j.1467-8306.2003.09304007.x

Palacios, J., García, M. \& Rico, J. (2013). Problematizando el turismo residencial europeo: tecnologías globales de gobierno y formas de subjetivación. Tabula Rasa (19), 167189. http://www.revistatabularasa.org/numero-19/08palacios.pdf

Ponce, M. E. (2010). El habitus del hacendado. Historia y Grafia (35), 51-91. http://www. scielo.org.mx/scielo.php?script=sci_arttext\&pid=S1405-09272010000200003 
Posada, M. (1999). El espacio rural entre la producción y el consumo: algunas referencias para el caso argentino. EURE, 25(75), 63-76. http://www.eure.cl/index.php/eure/article/ view/1199

Ragnedda, M. (2008). El consumismo inducido: reflexiones sobre el consumo postmoderno. Pensar la Publicidad, 2(1), 123-140. http://revistas.ucm.es/index.php/PEPU/article/ view/16409

Ramírez, E. (2012). El desarrollo del capitalismo en México en la segunda mitad del siglo XIX. Economia Informa (374), 26-52. http://www.economia.unam.mx/publicaciones/ econinforma/374/02estela.pdf

Ramírez, I. \& Osorio, M. (2010). Turismo residencial y desarrollo local en el Estado de México. En D. Hiernaux (Coord.), Las segundas residencias en México: un balance (pp. 145184). México: Plaza y Valdés.

Ramírez, I. \& Osorio, M. (2013). Bases para una aproximación a la ética y estética en el fenómeno turístico. Movilidad y nueva era. En C. Massé (Coord.), La complejidad autorreflexiva epistemológica de las ciencias sociales y su diversidad campotemática (pp. 241-256). México: Porrúa.

Real Academia Española (RAE). (2015). Diccionario de la lengua española. Versión en línea en http://www.rae.es/

Ren, C., Pritchard, A. \& Morgan, N. (2010). Constructing tourism research. A critical inquiry. Annals of Tourism Research, 37(4), 885-904. http://doi.org/10.1016/j. annals.2009.11.006

Royuela, M. \& Ramírez, I. (2015). Patrimonialización, desarrollo, gobernanza y gubernamentalidad en Malinalco, Pueblo Mágico. Cultur, 9(2), 92-116. http:// ri.uaemex.mx/handle/20.500.11799/32558

Rosenzweig, F. (1965). El desarrollo económico de México de 1877 a 1911. El Trimestre Económico, 32(127-3), 405-454. http://doi.org/10.18234/secuencia.v0i12.235

Sanguin, A-L. (1981). La géographie humaniste ou l'approche phénoménologique des lieux, des paysages et des espaces. Annales de Géographie, 90(501), 560-587. http://www. persee.fr/doc/geo_0003-4010_1981_num_90_501_20040

Santiago, F. (2012). Territorio y gobierno indio en Malinalco. Siglos XVI-XVIII. Tesis de Maestría, Universidad Nacional Autónoma de México, México:.

Schneider, L. M. (1999). Malinalco. Monografía Municipal. México: Instituto Mexiquense de Cultura.

Siniego, V. (s/f). Malinalco. México Desconocido. http://www.mexicodesconocido.com.mx/ malinalco-pueblos-magicos-de-mexico.html

Speckman, E. (2008). El Porfiriato. En P. Escalante, B. García Martínez, L. Jáuregui, J. Z. Vázquez, E. Speckman, J. Garciadiego \& L. Aboites, Nueva Historia Minima de México Ilustrada (pp. 337-391). México: Secretaría de Educación del Gobierno del Distrito Federal - El Colegio de México.

Tuan, Yi-Fu. (2003). Perceptual and Cultural Geography. A commentary. Annals of the Association of American Geographers, 93(4), 878-881. doi: 10.1111/j.14678306.2003.09304008.x

Wright, J. (1947). Terrae Incognitae: The place of imagination in Geography. Annals of the Association of American Geographers, 37(1), 1-15. http://www.colorado.edu/geography/ giw/wright-jk/1947_ti/body.html 
Zárate, V. (2005). Los privilegios del nombre, los nobles novohispanos a fines de la época colonial. En P. Gonzalbo (Dir.), Historia de la vida cotidiana en México. El siglo XVIII, entre tradición y cambio (pp. 325-356). México: Fondo de Cultura Económica El Colegio de México.

Zusman, P. (2013). La geografía histórica, la imaginación y los imaginarios geográficos. Revista de Geografia Norte Grande, (54), 51-66. http://dx.doi.org/10.4067/S071834022013000100004 